\title{
Mothers' perception of neonatal jaundice in Lagos, Nigeria: An urgent need for greater awareness
}

\author{
V C Ezeaka, MBBS, MPH, FWACP (Paed); E N Ekure, MB BCh, FWACP (Paed); I B Fajolu, MBBS, FMCPaed; \\ B N Ezenwa, MBBS, MPH, FMCPaed; P E Akintan, MBBS, FMCPaed
}

Department of Paediatrics, Lagos University Teaching Hospital, Nigeria

Corresponding author: V C Ezeaka (ezeakac@yahoo.com)

\begin{abstract}
Background. Neonatal jaundice remains a leading cause of preventable brain damage, mental handicap, physical disabilities and early death among infants. The high mortality and morbidity from neonatal jaundice is exacerbated by the poor understanding and mismanagement of this common neonatal problem by the general populace, leading to dangerous delays and complications.

Objective. To assess the knowledge of pregnant women on the causative factors, treatment modalities and sequelae of neonatal jaundice. Methods. Data were obtained from all consecutive women who attended the antenatal clinic of the Lagos University Teaching Hospital, Nigeria, from January 2013 to April 2013, using a pretested questionnaire focusing on knowledge of neonatal jaundice and its causes, treatment and complications.

Results. The study participants numbered 395, of whom 213 (53.9\%) were within the age range of 30 - 39 years. Only 101 (25.6\%) participants gave a correct definition of neonatal jaundice. The highest proportion of those who did not give a correct definition were from the lower socioeconomic groups V and IV $\left(\chi^{2}=12.08, p=0.017\right)$. Participants who did not know the causes numbered $313(79.2 \%)$, while $325(82.2 \%)$ participants chose ineffective treatment options. Furthermore, 296 (74.9\%) respondents, especially those with a low level of education, did not identify the complications correctly $\left(\chi^{2}=12.61, p=0.006\right)$.

Conclusion. Women in the study showed inadequate knowledge of and misconceptions regarding neonatal jaundice, which must be addressed in order to reduce significantly the devastating consequences of this common condition. We advocate for improved female literacy and mass health enlightenment programmes.
\end{abstract}

S Afr J Child Health 2016;10(4):227-230. DOI:10.7196/SAJCH.2016.v10i4.1190

Neonatal jaundice remains a leading cause of preventable brain damage, mental handicap, physical disabilities and early death among infants. ${ }^{[1-7]}$ This hyperbilirubinaemia results from a predisposition to bilirubin production in the newborn and their limited ability to excrete it. Infants, especially preterms, have higher rates of bilirubin production than adults because they have red cells with a shorter life span, a higher rate of haemolysis, inadequate caloric intake with increased enterohepatic circulation, and an underdeveloped conjugating system..$^{[1,4,8]}$

Apart from causing neonatal deaths and chronic handicapping conditions such as cerebral palsy, severe unconjugated hyperbilirubinaemia usually causes deafness, speech disorders, learning disabilities and mental retardation. ${ }^{[1-4,6-8]}$ Several studies in Nigeria have shown neonatal jaundice to be one of the most common neonatal emergencies in the referral centres, ${ }^{[3,9-11]}$ and some reports have shown that severe neonatal jaundice and kernicterus contributed to about a half of all cases of cerebral palsy. ${ }^{[2,12-14]}$ Furthermore, it has been reported that even moderate neonatal hyperbilirubinaemia may lead to mild neurological damage, which may not be obvious during the neonatal period, but manifests only in later life. ${ }^{[15]}$

The high mortality and morbidity from neonatal jaundice is exacerbated by the poor understanding, and mismanagement, of this common neonatal problem by the general populace, leading to dangerous delays and complications. ${ }^{[11,16-18]}$ The experience has been that the caregivers do not usually detect this potentially serious condition early, and in many situations the healthcare providers and the mothers are misguided about the conventional modalities of management, such that these infants consequently develop kernicterus. In view of the high two-thirds prevalence of home deliveries in our environment, the widespread practice of early hospital discharge for the approximately one-third of the mothers who deliver in the health facilities ${ }^{[19]}$ and the lack of effective postnatal follow-up health visits, there is a crucial need for mothers to be duly educated on the early detection of neonatal jaundice and the avoidance of precipitating factors. Mothers, who are usually the primary caregivers of the newborns, must possess basic knowledge pertaining to the aetiology and complications of neonatal jaundice, and must be given skills in its early diagnosis and management.

Most studies on neonatal jaundice in Nigeria have dwelt mainly on clinical research concentrating on the medical aetiological factors ${ }^{[2-4,7,8]}$ and on the management of neonatal jaundice by healthcare staff. ${ }^{[16,17]}$ In view of the real need for early detection and prompt institution of appropriate therapy, the present study aims to assess the perception of caregivers on the causative factors, treatment modalities and complications of neonatal jaundice. To our knowledge, this is the first study on the assessment of mothers' knowledge of neonatal jaundice in Lagos, Nigeria, and it will help to provide baseline data for the formulation of effective interventional measures.

\section{Methods}

This cross-sectional study was carried out at the Lagos University Teaching Hospital (LUTH), Nigeria, from January 2013 to April 2013. LUTH is a 750-bed tertiary hospital offering maternal and child health services to all ethnic, religious and socioeconomic populations of Nigerians within and outside Lagos State. The hospital is a referral centre for general hospitals, maternity facilities and private hospitals, within Lagos and its neighbouring states.

Data were obtained from all consecutive women who attended the antenatal clinic of the institution during the study period using a pretested questionnaire. Questionnaires were administered after obtaining informed consent from the mothers. Ethical approval was obtained from the Ethical Committee of the institution. The first section of the questionnaire included personal data, sociodemographic data, educational level attained and obstetric data of respondents. 
The next section of the survey instrument aimed to assess the knowledge of the mothers regarding the definition of neonatal jaundice and what it entails, possible causes, treatment modalities, complications and how to detect neonatal jaundice in the newborn, using closed- and open-ended questions of multiple choice types. The mothers were encouraged to seek clarification on any of the questions from the attending interviewer but discussion among them was discouraged while they were filling in the questionnaires. To avoid bias the interviewer only interpreted the question into the local language if mothers sought clarification, and then without further explanations.

Social classification criteria designed by Olusanya et al. ${ }^{[20]}$ were used. These comprise five social classes (I - V) according to a scoring system based on the mother's education and her husband's occupation. Social classes I and II represent the elites, class III is the middle class while class

Table 1. Sociodemographic characteristics of respondents

\begin{tabular}{ll}
\hline Variables & $\begin{array}{l}\text { Frequency, } \\
\boldsymbol{n}(\%)\end{array}$ \\
\hline Total & $395(100.0)$ \\
Age range (years) & \\
$15-19$ & $3(0.8)$ \\
$20-29$ & $167(42.3)$ \\
$30-39$ & $213(53.9)$ \\
$\geq 40$ & $12(3.0)$
\end{tabular}

Ethnicity

Ibo

Yoruba

$161(40.8)$

Hausa

Others

Education level

No formal education

Primary

Secondary

Tertiary

Social class

$$
\text { I }
$$

II

III

$126(31.9)$

145 (36.7)

$62(15.7)$

43 (10.9)

$19(4.8)$

V

$153(38.7)$

$228(57.7)$

$14(3.5)$
IV and V occupy the lowest rungs of the socioeconomic ladder.

The SPSS version 17.0 (IBM Corp., USA) statistical software was used for data entry, validation and analysis. Pearson's $\chi^{2}$ statistic was used to examine the association between categorical variables. Differences, associations and relationships were said to be statistically significant when $p \leq 0.05$.

\section{Results}

The number of respondents who participated in the study was 395 . Most of them were within the age range of 30 - 39 years (Table 1).

Of the 395 participants interviewed, 101 (25.6\%) correctly defined neonatal jaundice as a yellowish discoloration of the eyes and skin owing to accumulation of bilirubin, while 294 (74.4\%) mothers did not know the correct definition of neonatal jaundice. Table 2 shows the participants' definition of neonatal jaundice based on social classification. The results are statistically significant $\left(\chi^{2}=12.08, p=0.017\right)$.

Regarding the question on knowledge of the causes of jaundice in the newborn, 313 (79.2\%) participants answered that they did not know the causes, $43(10.9 \%)$ gave varied incorrect answers in different combinations, 27 (6.8\%) respondents attri-buted the newborn jaundice to mosquito bites while $3(0.8 \%)$ participants attributed the cause to yellow fever. However, only 39 (9.9\%) participants correctly identified the causes as blood incompatibility between mother and baby, infection in baby and prematurity. Of these, $13(33.3 \%)$ correctly identified one cause, while $20(51.3 \%)$ and $6(15.4 \%)$ correctly identified two and three causes, respectively.

Fig. 1 shows that in answer to the question on how neonatal jaundice should be effectively treated, $70(17.8 \%)$ of the participants said they had no knowledge. Of the 325 (82.2\%) participants who mentioned treatment options, 114 (35.1\%) incorrectly chose the use of ampiclox syrup, 87 (26.8\%) chose exposure to natural sunlight, while only $31(9.5 \%)$ correctly identified the use of a specific phototherapy machine, and $20(6.2 \%)$ chose exchange blood transfusion (EBT) as modalities of treatment. A combination of both phototherapy and exchange blood transfusion was chosen by 18 (5.5\%). Other treatment options reported by the subjects were the use of unripe pawpaw water $(28(8.6 \%))$, use of herbal medications (11 $(3.4 \%))$, glucose water $(7(2.2 \%))$ and varied combinations $(9(3.1 \%))$.

Furthermore, to the question about knowledge of complications of neonatal

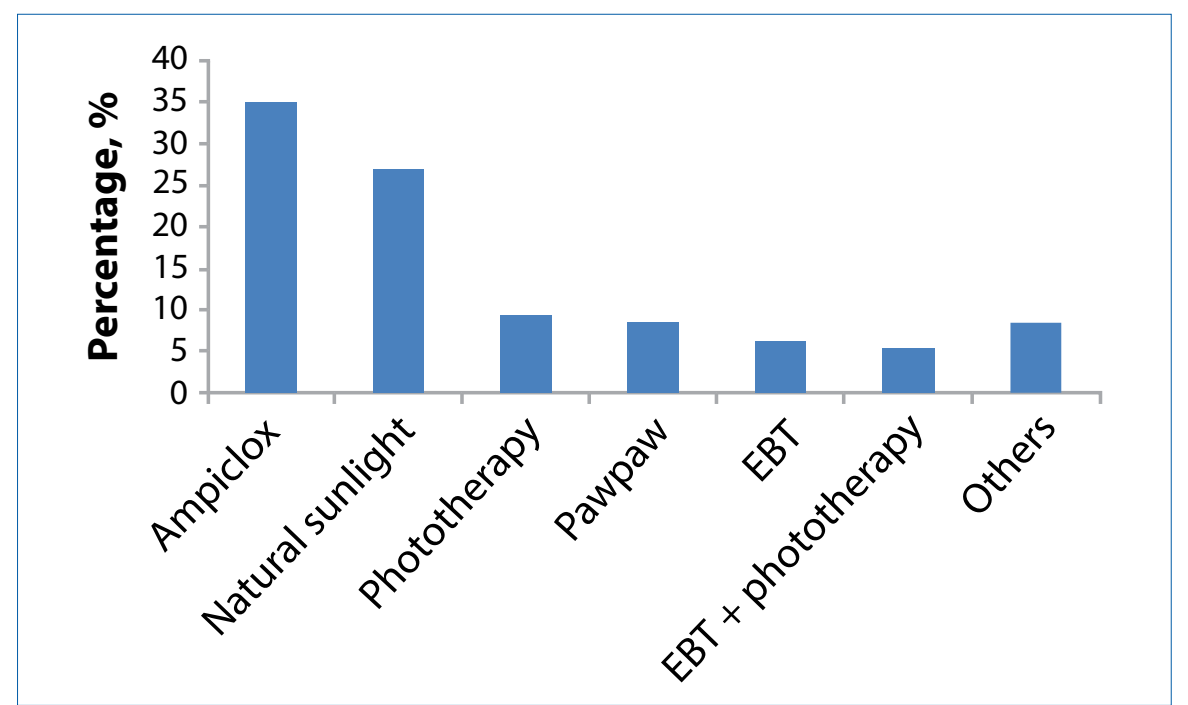

Fig. 1. Treatment options chosen by respondents.

Table 2. Participants' definition of neonatal jaundice by social classification

\begin{tabular}{llll}
\hline Social class & $\begin{array}{l}\text { Correct definition, } \\
\boldsymbol{n}(\boldsymbol{\%})\end{array}$ & $\begin{array}{l}\text { Incorrect definition, } \\
\boldsymbol{n}(\%)\end{array}$ & Total, $\boldsymbol{n}(\%)$ \\
\hline Total & $101(100.0)$ & $294(100.0)$ & $395(100.0)$ \\
I & $46(36.5)$ & $80(63.5)$ & $126(100.0)$ \\
II & $30(20.7)$ & $115(79.3)$ & $145(100.0)$ \\
III & $14(22.6)$ & $48(77.4)$ & $62(100.0)$ \\
IV & $8(18.6)$ & $35(81.4)$ & $43(100.0)$ \\
V & $3(15.8)$ & $16(84.2)$ & $9(100.0)$
\end{tabular}


jaundice, 99 (25.1\%) respondents correctly identified brain damage, mental retardation, hearing impairment, delayed development and convulsions in the baby as complications singly and in combinations, while 296 (74.9\%) participants did not correctly identify the complications. Of these 296 respondents, 263 (88.9\%) did not think they knew the complications, while $33(10.9 \%)$ respondents gave incorrect answers such as sickle cell anaemia, blindness and damage to the blood. These results are shown in Table 3 and are statistically significant $\left(\chi^{2}=12.61 ; p=0.006\right)$.

Regarding information received about neonatal jaundice, $185(46.8 \%)$ had never received any such information, 89 (22.5\%) admitted they had some information from health workers (either nurse or doctor), 68 (17.2\%) were informed by friends and relatives and only $16(4.05 \%)$ received information from the mass media (television and radio). Various combinations of the above options were given by 37 (9.4\%) of the respondents.

\section{Discussion}

Neonatal jaundice is the most common neonatal emergency and a significant contributor to neonatal morbidity and mortality in developing countries. However, in spite of its high prevalence, it is apparent from the present study that the mothers, who are the primary caregivers, have a poor understanding of this common, potentially lethal condition.

The finding that as many as $75 \%$ of the respondents could not describe correctly what neonatal jaundice entails is rather disheartening, since this translates to undue delays in identification and seeking appropriate care. The end result may be the development of severe brain damage in the affected baby. This corroborates studies by Ekanem et al. ${ }^{[16]}$ and Ogunfowora et al., ${ }^{[17]}$ although their studies centred on primary healthcare workers. The result that many of the mothers described newborn jaundice as malaria in the newborn is further evidence of this poor knowledge. Furthermore, the result that this knowledge gap is significantly wider in mothers from the lower socioeconomic group, who have poorer educational status, underscores the urgent need for improved female education and mass health enlightenment programmes on newborn jaundice.

In the same light, $>75 \%$ of the participants did not correctly identify the causes of neonatal jaundice despite the fact that blood group incompatibility, prematurity, infections and glucose-6-phosphate dehydrogenase deficiency have been reported by several authors in Nigeria as common aetiological factors. ${ }^{[3,7,8]}$ Furthermore, certain agents commonly used by the mothers in their homes, such as naphthalene balls, herbal drinks and drugs, have been documented to be icterogenic, causing an increase in the prevalence and severity of neonatal jaundice. ${ }^{[7,8]}$ Some respondents attributed the cause to yellow fever in the newborn. Therefore, while continuous research on clinical patterns and technologically advanced therapeutic options remain very relevant, there should be a major focus on formulating appropriate preventive and interventional strategies in the community.

More than half of the respondents incorrectly chose the use of ampiclox syrup (a combination of ampicillin and cloxacillin antibiotic), glucose drinks, unripe pawpaw water and exposure to sunlight, which have all been shown to be totally unreliable. Sadly, these same therapeutic options are among those chosen by primary healthcare workers from previous studies in Nigeria $>2$ decades ago. ${ }^{[16]}$ It is imperative that the healthcare system be strengthened, and better provision made for improved health education programmes in the community, as a matter of urgency. The ineffective treatment options widely practised by the mothers tend to create a false confidence, thus delaying institution of appropriate care and leading to devastating consequences for the infant. Regarding the complications, it was not surprising that most of the mothers were not well-informed since most were not aware of what the disease entailed or the possible causative agents. The knowledge gap is significantly more evident in mothers with lower educational
Table 3. Respondents' knowledge of the complications of neonatal jaundice by education level

\begin{tabular}{llll}
\hline $\begin{array}{l}\text { Educational } \\
\text { level }\end{array}$ & $\begin{array}{l}\text { Correct } \\
\text { knowledge, } \boldsymbol{n}(\%)\end{array}$ & $\begin{array}{l}\text { Incorrect } \\
\text { knowledge, } \boldsymbol{n}(\%)\end{array}$ & $\begin{array}{l}\text { Total, } \\
\boldsymbol{n}(\%)\end{array}$ \\
\hline Total & $99(25.1)$ & $296(74.9)$ & $395(100.0)$ \\
$\begin{array}{l}\text { No formal } \\
\text { education }\end{array}$ & $0(0.0)$ & $6(100.0)$ & $6(100.0)$ \\
Primary & $1(4.5)$ & $21(95.5)$ & $22(100.0)$ \\
Secondary & $36(21.2)$ & $134(78.8)$ & $170(100.0)$ \\
Tertiary & $62(31.5)$ & $135(68.5)$ & $197(100.0)$
\end{tabular}

status, while overall a quarter of the respondents correctly identified brain damage, mental retardation and delayed development as complications. This poor understanding of the dangers of jaundice on the brain of the newborn infant further trivialises the mother's management of this silent crippling condition.

Neonatal jaundice occurs in most newborns and the hallmark of effective treatment is early identification and appropriate therapy. In developed countries, the menace of newborn jaundice has received better priority and attention. In the USA, the national healthcare organisations including the Centers for Disease Control, the Joint Commission for the Accreditation of Healthcare Organizations and the American Academy of Pediatrics issued alerts to all accredited hospitals and public health professionals that all healthy infants are at potential risk of kernicterus if their newborn jaundice is unmonitored and inadequately treated. ${ }^{[6]}$ However, in many developing countries, compared with many conditions that require advanced pharmacological strategies, newborn jaundice seems to be overshadowed, and has lost the attention that it deserves as a condition that has potentially deleterious consequences.

Intensive health education campaigns on neonatal jaundice should be instituted at antenatal clinics, immunisation clinics, paediatric clinics, well-baby clinics and in all health centres in the community. This is to ensure that mothers are duly educated at every opportunity about the causes of neonatal jaundice. Areas in which to concentrate in jaundice education should include the possible triggers of haemolysis that are commonly used in the homes, such as menthol and naphthalene balls, how newborn jaundice can be identified early and effective treatment options for neonatal jaundice. This is especially pertinent as many newborns are usually discharged home $<48$ hours after birth, when the jaundice is not yet evident. These new mothers are left at the mercy of grandmothers and neighbours who recommend local remedies such as pawpaw water and herbal medications. The mass media should be involved in mass mobilisation campaigns to help avert this apparent lack of awareness as the present study has shown that only a negligible proportion of the respondents received information about neonatal jaundice from that source. Increased knowledge about the predispositions and consequences of severe hyperbilirubinaemia by the mothers is imperative for the institution of early appropriate care, thereby reducing significantly the menaces from the devastating disabilities of this condition in our communities.

\section{References}

1. Stoll BJ, Kliegman RM. Jaundice and hyperbilirubinaemia in the newborn. In: Behrman RE, Kliegman RM, Jenson HB, eds. Nelson Textbook of Paediatrics. Philadelphia: WB Saunders Company, 2005:513-519.

2. Belonwu RO, Gwarzo GD, Adeleke SI. Cerebral palsy in Kano, Nigeria - a review. Niger J Med 2009;18(2):186-189. http://dx.doi.org/10.4314/njm.v18i2.45062

3. Owa JA, Osinaike AI. Neonatal morbidity and mortality in Nigeria. Indian J Pediatr 1998;65(3):441-449. http://dx.doi.org/10.1007/bf02761140

4. American Academy of Pediatrics Subcommittee on Hyperbilirubinemia Management of hyperbilirubinemia in the newborn infant 35 or more weeks of gestation. Pediatrics 2004;114(1):297-316. http://dx.doi.org/10.1542/peds.114.1.297 
5. Watson RL. Hyperbilirubinemia. Crit Care Nurs Clin North Am 2009;21(1):97120. http://dx.doi.org/10.1016/j.ccell.2008.11.001

6. Bhutani VK, Johnson LH. Newborn jaundice and kernicterus - health and societal perspectives. Indian J Pediatr 2003;70(5):407-416. http://dx.doi. org/10.1007/bf02723615

7. Ogunlesi TA. Managing neonatal jaundice at the general practice and primary health care level: An overview. Nig J Paed 2004;31(2):33-38. http://dx.doi. org/10.4314/njp.v31i2.12086

8. Olusanya BO, Emokpae AA, Zamora TG, Slusher TM. Addressing the burden of neonatal hyperbilirubinaemia in countries with significant glucose-6phosphate dehydrogenase deficiency. Acta Paediatr 2014;103(11):1102-1109. phosphate dehydrogenase deficiency.

9. Ransome-Kuti O. Problems of paediatric emergencies in Nigeria. Nig J Med 1972;2:62-70

10. Lesi FEA, Temiye EO, Epelle TGS. The changing pattern of childhood mortality in the children's emergency room of the Lagos University Teaching Hospital after 20 years. Niger Med J 2000;38(2):38-41.

11. Ezeaka C, Ogunbase AO, Awogbemi OT, Grange AO. Why our children die: A review of paediatric mortality in a tertiary centre in Lagos, Nigeria. Nig Qt J Hosp Med 2003;13(1-2):17-21. http://dx.doi.org/10.4314/nqjhm.v13i1.12502

12. Animashaun A. Aetiology of cerebral palsy in African children. Afr J Med Sci 1971;2(2):165-171.
13. Duggan MB, Ogala W. Cerebral palsy in Nigeria: A report from Zaria. Ann Trop Paediatr 1982;2(1):7-11.

14. Asindi AA. The pattern of neurological disabilities in children seen at the University of Calabar Teaching Hospital. Nig J Paediatr 1988;13:127-132.

15. Naeye RL. Amniotic fluid infections, neonatal hyperbiliubinaemia and psychomotor impairment. Paediatrics 1978;62(4):497-503.

16. Ekanem EE, Young MU. Knowledge of the causes and management of neonatal jaundice by primary health care staff. Niger J Paed 1994;21(2):37-42.

17. Ogunfowora OB, Daniel OJ. Neonatal jaundice and its management: Knowledge, attitude and practice of community health workers in Nigeria. BMC Public Health 2006;6:19. http://dx.doi.org/10.1186/1471-2458-6-19

18. Owa JA, Ogunlesi TA. Why we are still doing so many exchange blood transfusion for neonatal jaundice in Nigeria. World J Pediatr 2009;5(1):51-55. http://dx.doi.org/10.1007/s12519-009-0009-2

19. National Demographic and Health Survey 2008. National Population Commission and ORC Macro, Calverton, MD, 2004.

20. Olusanya O, Okpere E, Ezimokhai M. The importance of social class in voluntary fertility control in a developing country. W Afr J Med 1985;4:205-212.

Accepted 12 August 2016 